\title{
Rural Public Space: A New Way to Awaken the Vitality of Governance
}

\author{
Tianyi Wang ${ }^{1, *}$ Jun $\mathrm{Liu}^{2}$, Tong $\mathrm{Wu}^{3}$ \\ ${ }^{1}$ School Marxism, Wuhan University of Technology, Wuhan, Hubei, China, 430000 \\ ${ }^{2}$ School Marxism, Wuhan University of Technology, Wuhan, Hubei, China, 430000 \\ ${ }^{3}$ School Marxism, Wuhan University of Technology, Wuhan, Hubei, China, 430000 \\ *Corresponding author.Email: wilheim@foxmail.com ${ }^{1}$,76737306@qq.com²,2399807332@qq.com
}

\begin{abstract}
The proposal of Rural Revitalization Strategy points out the direction of strengthening rural governance in the new era, but rural governance still faces problems such as the participation of the masses in rural governance is not active and the foundation of mass autonomy is not reliable. Public space has existed in the rural land for a long time, and has experienced many changes since modern times, and now it is showing a trend of decline and atrophy. The functions of rural public space, such as helping rural order construction, promoting rural multiple order dialogue, and solving the "free riding" problem, make it a powerful role in optimizing rural governance and promoting the realization of mass autonomy. In order to reconstruct the public space, we should pay attention to the construction and maintenance of existing resources, and encourage non-governmental organizations to participate in the construction and play the role of new technology like social media.
\end{abstract}

Keywords: public space, rural, rural governance, Rural Revitalization

\section{QUESTIONS RAISED}

The report of the 19th National Congress of the Communist Party of China emphasizes that the problems of agriculture, rural areas and farmers are fundamental issues related to the national economy and the people's livelihood. We must always take the "three rural" issues as the top priority of the whole Party's work, and the Rural Revitalization Strategy has been formally put forward. In 2020, Central Document 1 clearly pointed out that the promotion of rural governance should attach importance to mass mobilization and give full play to the initiative of the masses. In the new rural governance system under the leadership of the party organization and the combination of "three governance", the masses have always been an important link in the realization of the system. To stimulate the enthusiasm of villagers, it is necessary to awaken public awareness and reshape the identity of village community. In China's rural society in the rapid transformation period, the lack of such identity and enthusiasm is directly related to the village's inability to give full public care to individuals. Therefore, reshaping the public life of the village is the only way to improve the supply of public care, enhance the cohesion of the village and the public identity of the villagers, so as to improve the enthusiasm of the villagers to participate in governance and even realize the revitalization of the countryside.

\section{PUBLIC SPACE IN CHINA}

Village community identity needs to be established under a certain field, which must be public. In this field, people can fully express their concern about public issues, and this field also becomes the intersection of people's life, thus producing public life. The concept of "Public sphere" was first put forward by Arendt, a German female thinker. Habermas carried forward the concept ${ }^{[1]}$. He believed that "public sphere" is "the space for citizens to discuss public affairs and participate in politics freely as the basic conditions of democratic politics, besides political power". In a sense, public space is not only a field with functions and functions of public sphere, but also a field with practical sense of space, which is the embodiment of public sphere.

In the context of village governance, based on the connotation of Habermas concept, it should bear the function of accommodating the activities of national and social forces, constructing order and reaching consensus. As the most easily concentrated way of opinions, rural 
public space in China has an important position in history. Under the natural economic conditions, the public space with blood ties as the link and Presbyterian politics as the expression form is an endogenous public space based on the internal self-development power of the countryside. It mainly carries the construction of kinship ethics system, the intersection of agricultural production information, and the satisfaction It can meet people's natural social entertainment needs, convey the political orders of the county government, and realize the four major functions of village internal autonomy.

Taking the Third Plenary Session of the Eleventh Central Committee of the Communist Party of China as the node, the development of rural public space has been affected by many aspects: first, the household contract responsibility system has been spread across the country, the basic unit of agricultural production has changed from collective farm to contracted to household, the relevance of rural collective interests is reduced, and the development of external market economy is of great significance to the development of rural public space. With the impact of rural values, the rural value system is gradually monetized, while the stratum differentiation, the kinship ethics structure gradually disintegrates, showing the trend of atomization ${ }^{[2]}$; the second is a large number of rural population move out, resulting in rural hollowing out, aging phenomenon is becoming increasingly serious; third, after the tax reform and the separation of land three rights, there is a fracture between the village collective and the villagers ${ }^{[3]}$. Fourth, the popularity of water supply, washing machines, air conditioning and other facilities has made the public space characteristics of the former residential areas such as wells and tree shade ${ }^{[4]}$. Under the multiple effects of these factors, the status of villages in public life has declined, the existing public space has been shrinking.

\section{RURAL ORDER, RURAL GOVERNANCE AND PUBLIC SPACE}

\subsection{The order dialogue within the village}

The construction of rural order needs consensus, and the generation of consensus should be based on the contact between people. People have similar living background and similar living conditions. People who grow up in similar environment tend to have similar behavior styles and values, which is the best soil for identification. At the same time, the generation of identity and order is not a matter of a moment. On the contrary, years of collision and confrontation are the source of the generation of rural order. No matter the "elite order" dominated by elites or the "grassroots order" led by ordinary farmers, the leading forces must be based on a certain background of the times, through the interaction between the political power outside the village and the endogenous force in the village, In the process of this complex variable participation, the public domain is the main battlefield. The emergence of order needs the coordination of material and non-material. In the field of rural areas, any place with public nature can become a place to discuss public issues. Consensus is generated in the context of this discussion, and the village order is shaped by the interaction of forces.

\subsection{Solve the free-riding problem}

Compared with the western society, the boundary between "public" and "private" in China's rural society is extremely vague, with the characteristics of "differential order pattern"[5]. The tendency of egoism interacts with each other, there is a vacuum zone that is not taken into account after all the individual structures are interlaced. Most of these vacuum areas are public affairs that need extensive participation. The interests can be shared, but the costs can't be shared. The enthusiasm of the public to participate in public affairs can't be mobilized, and the realization of "public governance" is out of the question. The public space in China's rural areas is all interposed in every scene of people's daily production and life. Restricted by time and space, people will take geography as the clue and invest in the appropriate public space within their own ability range, thus forming a "small circle". The smaller the group size is, the stronger the ability of invisible supervision among members is, and the opportunistic behavior is convenient There is no escape. From the perspective of the village as a whole, the atomized villagers are integrated into several small groups because of the existence of public space. Because of the identity of space production, the group has a high degree of homogeneity, which highlights the heterogeneity among groups, greatly integrates the diversified interest orientation and reduces the governance cost of the village.

\subsection{Solving the confusion of the conflict between the country and the country}

At first, the concept of public sphere was used to discuss the relationship between society and state in order to analyse the operation mechanism of state power order and endogenous order of local society. Since the state officially abolished the agricultural tax in 2006 and implemented the tax reform, the relationship between the state and farmers has gradually changed from "absorbing type" to "service-oriented" relationship. The village administrative expenditure is responsible by the county and township finance, which represents the country. The system of "the first village secretary" implemented in 2010 has become an external embedding. As the representative of order, the sinking of state power to the countryside has become a historical necessity. However, this kind of subsidence is bound to squeeze the original space of village autonomy. The self-government organization is administrated and the village cadres are out of work. On the surface, it is the state power that 
supports the rural development. However, the county and township level which truly represents the national power is far away from the local people, which affects the final realization of "good governance". The public space has the ability to realize dialogue and bridge differences. Making good use of the public space's leading role in public opinion and turning the public space into a gateway to observe the people's situation and understand the actual situation of the village can effectively avoid the village cadres' work from being divorced from the rural reality, and can also convey the true voice of the masses, and promote the scientific and rational rural autonomy.

\section{PURSUIT OF PUBLICITY: RESEARCH ON THE PATH OF PUBLIC SPACE CONSTRUCTION IN THE NEW ERA}

The core of public space lies in publicity. According to the above, the main reason for the decline of rural public space is the continuous loss of publicity. In the increasingly hollowed out "society without subject Acquaintances"[6], the proportion of public life in Villagers' daily production and life is getting smaller and smaller, and the corresponding sense of identity to the village is also weakening. It is imperative to restore publicity and reconstruct public space.

\subsection{Pay attention to the construction and maintenance of existing resources}

First of all, rural public space in geographical sense includes village geographical indications such as wells, stage and tree shade. Some scholars also point out that some intangible cultural activities in villages, such as weddings and funerals, also have the function of public space $^{[7]}$. What they have in common is that they can become the carrier and media of public activities. Under the background of aging and atomization in rural areas, repairing the existing public space can not only save construction costs, but also avoid villagers' resistance to new things. By renovating the old facilities and holding new activities, the attraction to the villagers can be enhanced, so that they can gather together, so as to strengthen the social connection of the villagers, wake up the common memory hidden in the hearts of the villagers, so as to cultivate a renewed local identity. Secondly, we should make good use of the commercial units such as small shops. Because such units are closely related to the daily life of villagers, villagers often meet here, and over time form behavioral inertia. They gather here to play, exchange information and express their views on public affairs. Intangible production of value, public opinion, the formation of identity, the interaction between individuals, enhance the villagers' enthusiasm to participate in public affairs.

\subsection{Encourage nongovernmental organizations to participate in the construction of public space}

There are a variety of non-governmental organizations in villages, including production cooperatives, industry associations, cultural organizations, etc. these rural organizations have public places, public authority, public activities, public resources, rules and regulations, stable organizational structure and certain personnel participation, which are the logical basis for generating public space ${ }^{[8]}$. In the organized collective action, the village identity and value norms are maintained, and the cohesion is greatly enhanced. By giving full play to the advantages of small groups in village governance and avoiding the "hitchhiking problem", people can effectively solve the "atomization" problem and enhance the cohesion of the village.

\subsection{Play the role of science and technology to build a new type of public space}

Since the new century, the infrastructure construction in China has developed rapidly. With the "village and village communication" project as the representative, the Internet has entered every family in the vast rural areas. The new media technology has been popularized rapidly, Internet plus government service has become a new way to strengthen rural governance in the new era. The new information technology introduces new opportunities to participate in public affairs, so that those who are not so inclined and interested in public life can get involved. With the rapid rise of social media or digital technology tools, the network social movement is rising rapidly and has become an important form of people's involvement in public affairs. Mobile communication and new media to strengthen social relations can enhance the positive connection between information use and political participation. Village collective can consciously use instant messaging software and micro video platform to construct a new public space on the network, transmit information, carry out propaganda, broaden the forms of village cultural activities and enrich villages in the new era Cultural connotation can enhance the identity and cohesion between villagers and villages, shorten the space-time distance of villagers, strengthen the social connection within the village, and re-stimulate the value production vitality within the village with the Internet.

\section{CONCLUSION}

Rural public space has existed for a long time in China's rural areas. It has been developed and declined. In recent years, the support of the party and the state to rural areas, especially the proposal of "Rural Revitalization Strategy", has created excellent opportunities for the revival of public space. As an 
important auxiliary to promote villagers' autonomy and optimize rural governance, public space is bound to play an irreplaceable role in developing rural areas Public space is bound to arouse the enthusiasm of villagers to participate in public affairs, stimulate the endogenous vitality of village governance, and contribute to the realization of "good governance" and even the final realization of Rural Revitalization. Of course, as Zhou Shangyi said, each rural public space has its own planning and rules ${ }^{[9]}$. What this paper discusses is a general topic. Diversity brings more possibilities, which is worth our continuous research and exploration.

\section{ACKNOWLEDGMENTS}

This paper is supported by the Soft Science Project of Hubei Science and Technology Department in 2019 (2019ADC046) and "the Fundamental Research Funds for the Central Universities (WUT:2019VI040) and National innovation and entrepreneurship training program for college students (202010497052).

\section{REFERENCES}

[1] Habermas: structural transformation of the public sphere [M]. Trans. Cao Weidong, et al. Shanghai Xuelin press, 1999: 156. (in Chinese)

[2] Shu Yongyong, Zhai Qingfei. Development of rural grassroots democracy under the background of New Socialist Countryside Construction -- Based on the perspective of social public space [J]. Social scientist, 2013 (01): 49-52. (in Chinese)

[3] Wang Yong, Li guangbin. Fission and regeneration: Research on rural public space transformation in southern Jiangsu [J]. Urban development research, 2014,21 (07): 112-118. (in Chinese)

[4] Dong leiming. Shrinking and expanding of village public space $[\mathrm{J}]$. Journal of Jiangsu University of administration, 2010 (05): 51-57. (in Chinese)

[5] Fei Xiaotong. Local reconstruction of fertility system in China [M]. Beijing: Commercial Press, 2011:25-33. (in Chinese)

[6] Wu Chongqing. From acquaintance society to "no subject acquaintance society" [J]. Reading, 2011 (01): 19-25. (in Chinese)

[7] Xu Yong, Wu Yi, Sun long, Tong Zhihui, Xiao Lihui. Rural social observation (5 articles) [J]. Zhejiang academic journal, 2002 (02): 90-98. (in Chinese)

[8] Zhang Chungang, Jia Liping, Qi GuBo. Rural public space: unexpected consequences of cooperative development $[\mathrm{J}]$. JOURNAL OF NANJING AGRICULTURAL UNIVERSITY (SOCIAL SCIENCE EDITION), 2014,14 (02): 8-14. (in Chinese)
[9] Zhou Shangyi, long Jun. rural public space and rural cultural construction: a case study of rural public space in Tangshan, Hebei Province [J]. Hebei academic journal, 2003 (02): 72-78. (in Chinese) 